\title{
Morphometric Study of Myocardial Changes During Doxorubicin-induced Cardiomyopathy in Mice
}

\author{
WIM J.F. VAN DER VIJGH, ${ }^{*}$ DICK VAN VELZEN, $†$ JOS S.E. VAN DER POORT, ${ }^{*}$ HENNY M.M. \\ SCHLÜPER, ${ }^{*}$ KLAUS MROSS, ${ }^{*}$ JAN FEIJEN and HERBERT M. PINEDO \\ *Department of Oncology, Free University Hospital, Amsterdam, The Netherlands, †Department of Pathology, SSDZ, Delft, The \\ Netherlands and $\ddagger_{+}$Department of Chemical Technology, Twente University of Technology, Enschede, The Netherlands
}

\begin{abstract}
Doxorubicin (DOX) is one of the most effective anti-cancer drugs in oncology, but may cause a cumulative dose-dependent cardiomyopathy in a number of cancer patients. The effect of DOX on the heart was studied in mice trealed with i.v. injections of $2 \mathrm{mg} / \mathrm{kg}$ by measuring morphometric parameters, including nuclear index (number of non-myocytes/number of myocyte nuclei), reticulin index (reticulin area/number of myocyte transsections), nuclear transsectional area, myocyte transsectional area, capillary index (number of capillaries/number of myocyte transsections) and capillary transsectional area. The highest significant difference between control mice and DOX-treated mice was observed immediately after the 12 th dose of DOX except for the two capillary parameters. The highest level of significance for these two parameters was obtained 12 weeks after the end of DOX treatment. In contrast to the observations in rats, mice did not develop a nephrotic syndrome during treatment with DOX. The morphometric analysis of myocardial changes in mice, as a quantitative and objective method, seems to be a good model for comparative studies on cardiomyopathy induced by anthracycline analogues.
\end{abstract}

\section{INTRODUCTION}

ThE UTILIZATION of anthracycline antibiotics in clinical oncology is limited because of dose-related cardiotoxicity. The magnitude of this clinical problem is particularly great for breast cancer, where the decision to apply this anticancer drug in studies of adjuvant chemotherapy must be balanced against the risk of cardiotoxicity in a group including potentially cured individuals. Cardiotoxicity has been observed in man and animals, although species differences exist [1-3]. The rabbit and monkey have been reported to exhibit congestive heart failure associated with cardiomyopathy [4]. There is a lack of understanding of the causative mechanisms of anthracycline cardiotoxicity. Possible strategies

Accepted 24 May 1988.

This work was supported in part by grant no. THT 80-2 awarded by the Netherlands Cancer Foundation (KWF). Klaus Mross is a recipient of an EORTC fellowship.

Abbreviations used: DOX, doxorubicin; NI, nuclear index; $\mathrm{RI}$, reticulin index; NTA, nuclear transsectional area; MTA myocyte transsectional area; CI, capillary index; C'TA capillary transsectional area; $\mathrm{AU}$, arbitrary units.

Address for reprints and correspondence: Dr.W.J.F. van der Vijgh, Department of Oncology, University Hospital, Vrije Universiteit, De Boelelaan 1117, NL-1081 HV Amsterdam. The Netherlands. that may circumvent this cardiotoxicity include the development of anthracycline analogues with reduced cardiotoxicity, alteration of the schedulc and development of cardioprotective agents.

Billingham et al [5] have introduced a numerical grading system for the recording of morphological cardiac changes following treatment with anthracyclines. A similar scoring system was used by Bertazolli et al. [1] in a mouse model. Obviously, it is a prerequisite to use an unambiguous animal model and sensitive parameters of cardiotoxicity for any research in this area. Several authors have described morphological, biochemical and functional alterations in the heart induced by anthracyclines [5-7]. The morphological parameters have been shown to develop early and to be most reliable for detecting drug-related cardiomyopathy [3]. In order to establish a causative relationship between the drug and the morphological changes, the findings in laboratory animals should be reproducible. We have shown in a recent study that rats should not be used for cardiotoxicity studies on anthracyclines because they develop a severe nephrotic syndrome. In puromycin-treated rats, a common model for the nephrotic syndrome, cardiac damage was observed simi- 
W.J.F. van der Vigh et al.

lar to that observed in DOX treated rats $[8,9]$. In the present study cardiotoxicity was evaluated in mice by quantification of histomorphological characteristics from areas in transsectional sections of the heart after DOX treatment. Special attention was also directed to urinary protein excretion. The data indicate that the evaluation of anthracycline cardiotoxicity in mice can be carried out by a quantitative morphometric approach.

\section{MATERIALS AND METHODS}

Seventy-eight female Swiss mice (Central Institute for Experimental Animals, Zeist, The Netherlands) with an average weight of $25 \pm 2 \mathrm{~g}$ were randomly distributed into a control group (31 animals) and a DOX-treated group (48 animals). Mice were maintained in plastic cages in a standardized environment and fed a laboratory diet and water ad libitum.

Doxorubicin, dissolved in saline, was injected i.v. twice a week (Monday and Thursday) at a dose of $2 \mathrm{mg} / \mathrm{kg} /$ day 12 times. A treatment-free interval of 2 weeks was introduced after the 4 th injection in order to allow recovery of bone marrow function. Six DOX-treated mice and six control animals were killed at the following time points (in control groups $\mathrm{V}$ and VII only 3 and 4 animals respectively were killed): 1 week (DOX I, C I) 2 weeks (DOX II, C II), 6 weeks (DOX III, C III), 8 weeks (DOX IV, C IV), 12 weeks (DOX V, C V), 14 weeks (DOX VI), 16 weeks (DOX VII, C VII) and 20 weeks (DOX VIII).

Every week DOX-treated mice were randomly selected and kept in metabolic cages for $24 \mathrm{~h}$. Urine volume was measured and urine protein excretion was determined with the Bio-Rad protein assay (Bio-Rad Laboratories, Richmond, Cal., U.S.A.), in order to exclude the presence of a nephrotic syndrome. The hearts were quickly removed from the mice at thoracotomy, which was performed under ether anaesthesia, and immersed in $10 \mathrm{mM}$ $\mathrm{CaCl}_{2}$ solution for $5 \mathrm{~min}$. Subsequently, each heart was fixed in $2 \%$ glutaraldehyde in $0.1 \mathrm{M}$ phosphate buffer al PII 7.4 for $48 \mathrm{~h}$. All hearts were cut in a transverse plane, perpendicular to the ventricular septum, three times with the first transsection $2 \mathrm{~mm}$ below the cardiac skeleton.

The first slice of $1 \mathrm{~mm}$ thickness at the apical side of the first plane was processed for paraffin embedding with a standard technique. Paraffin sections of $4 \mu \mathrm{M}$ were cut and stained with haematoxylin and eosin (HE staining). A second slice of $0.5 \mathrm{~mm}$ thickness was cut on the skeletal side of the first plane and processed in methacrylate according to standard procedures. After embedding, semi-thin sections of $1 \mu \mathrm{m}$ were cut and stained with toluidine blue or PAS or Gomorri's silver stain.
Nuclear index $(N I)$

From each heart, three areas stained with $\mathrm{HE}-$-left ventricular free wall subendocardial, left ventricular papillary muscle and left ventricular septum subendocardial-were photographed twice on a $35 \mathrm{~mm}$ diapositive film using a $200 \times$ microscopic magnification. Colour slides were projected on a $120 \times 80$ screen subdivided by black lines into $10 \times 10 \mathrm{~cm}$ squares. Colour slides were analysed by counting non-myocyte nuclei and myocyte nuclei per square. The slides-two per area-were randomly selected. The origin of the specimen was unknown to the investigator. The nuclear index which is the ratio between the number of nonmyocyte nuclei and that of the myocyte nuclei, was calculated for all three locations of each heart.

\section{Reticulin index $(R I)$}

Paraffin sections were stained with Gomorri's silver stain and photomicrographs with a microscopic magnification of $400 \times$ were made on $35 \mathrm{~mm}$ Agfa Ortho 25 ISO film. Again, the three areas in each heart were analysed in duplicate. The negatives were magnified to prints of $6 \times 9 \mathrm{~cm}$. The nuclei visible in the prints were cut out. Reticulin areas were measured by a Quantimet (Cambridge Instruments, Milbourne, Royston, U.K.) with a fixed threshold setting. The RI was calculated as the ratio of reticulin area and number of myocyte transsections. The average RI was determined for each group of animals.

Nuclear and myocyte transsectional areas (NTA, MTA)

Photographs of PAS stained semi-thin sections were enlarged to $30 \times 40 \mathrm{~cm}$ with a microscopic magnification of $400 \times$. Cells transsected in the nuclear zone were identified by number. These cells were outlined on a digitizing tablet (Bit-pad, Summagraphics, on-line to a PDP-1173 computer) as were their nuclei. Two photographs per area were necessary to obtain the minimum sample size. Mean MTA and N'TA were calculated for all animal groups.

Capillary transsectional area (CTA) and capillary index (CI)

The same photographs as used for the determination of the MTA and NTA were analysed for CTA and CI. The capillaries were outlined on a digitizing tablet. Mean CTA was calculated for each animal group. The CI was calculated by dividing the total number of capillaries by the number of myocyte transsections. This index was determined for all animal groups.

\section{Statistical methods}

Differences between DOX and control groups were analysed by Wilcoxon's rank sum test. The 
minimal sample size was determined by the running mean method. Reproducibility and other statistical parameters related to the reliability of morphometric measurements have been reported previously [8].

\section{RESULTS}

\section{Protein excretion, urinary output and body weight}

During the experiment no nephrotic syndrome was observed in the DOX-treated mice. Mean urinary protein was $0.82 \pm 0.28 \mathrm{mg} / 24 \mathrm{~h}$ in the control group and $0.85 \pm 0.28 \mathrm{mg} / 24 \mathrm{~h}$ in the DOX groups. Mean urine volume was $6.6 \pm 2.8$ $\mathrm{ml} / 24 \mathrm{~h}$ in controls and $5.6 \pm 4.0 \mathrm{ml} / 24 \mathrm{~h}$ in the DOX group. There was no significant difference between controls and DOX-treated mice. Body weight was constant during DOX administration. Mean body weight was $27.5 \pm 0.4 \mathrm{~g}$ in the control group and $28.4 \pm 0.5 \mathrm{~g}$ in the DOX groups, which is not statistically different.

\section{Morphometric analysis}

The results obtained with the morphometric parameters of heart tissues of DOX-treated mice and controls are summarized in Table 1. All six parameters examined in this study changed as a result of the DOX treatment. During the period of DOX treatment the values of NI, RI, NTA and MTA steadily increased. After the period of DOX administration there was a slight decrease in NI, an impressive decrease in MTA and a plateau in NTA and RI. In the control groups NTA and MTA remained stable, while NI and RI gradually increased. NI and the NTA reached the highest level of significance $(P<0.001)$ after administration of 16 and $24 \mathrm{mg}$ DOX. RI and MTA reached the highest level of significance $(P<0.01)$ after the administration of 16 and $24 \mathrm{mg}$ DOX. The first significant differences $(P<0.05)$ between DOX and control groups were found after 2 weeks, i.c. at a cumulative dose of $8 \mathrm{mg}$ DOX.

In contrast to the four parameters mentioned above it appeared that the pattern of CI and CTA was different. CI increased in the DOX-treated group and did not become significantly different to that of the control group until 8 weeks, while the highest level of significance was reached after 20 wecks. The increase in CI correlated with a gradual increase in the number of capillaries present at the start of the experiment. In the initial wecks CI increased slightly in the control group, while it reached a platcau value after 6 wecks. CTA decreased constantly in the ADM groups. The highest level of significance $(P<0.01)$ was reached in the 20th weck. In the control group a slight increase was observed followed by a very slow decrease.

Figure 1 shows the result of NI, RI and CI while Fig. 2 gives the NTA, MTA and CTA data expressed in arbitrary units (AU) calculated by the computer from digitized data. The graphs show mean \pm S.E.M.

\section{DISCUSSION}

Recently we have shown [9] that rats with a nephrotic syndrome caused by puromycin develop changes in heart morphology similar to those of DOX-treated rats, a finding which questions the value of this species as a model to study DOXinduced cardiotoxicity [8]. Our present findings show that, in contrast to rats, mice do not develop a nephrotic syndrome during DOX treatment, indicating a species related variation in DOX-induced nephrotoxicity. These observations suggest that the mouse model is a better candidate for studying DOX-induced cardiomyopathy. Morphological changes following anthracycline treatment have

Table 1. Histomorphometric parameters of cardiomyocytes in mice during and after treatment with DOX compared to controls

\begin{tabular}{|c|c|c|c|c|c|c|c|c|c|}
\hline Groups & $\begin{array}{c}\text { No. of } \\
\text { animals } \\
n\end{array}$ & $\begin{array}{l}\text { No. of } \\
\text { wecks } \\
n\end{array}$ & $\begin{array}{l}\text { Cumulative } \\
\text { DOX dose } \\
\text { (ang/kg) }\end{array}$ & $\begin{array}{c}\text { Nuclear } \\
\text { index } \\
\text { (ntean } \pm \text { S.D.) }\end{array}$ & $\begin{array}{c}\text { Rcticulin } \\
\text { index } \\
\text { (mean } \pm \text { S.D.) }\end{array}$ & $\begin{array}{c}\text { Nuclear } \\
\text { transsectional } \\
\text { alca }(\mathrm{AU}) \\
\text { (mean } \pm \text { S.D.) }\end{array}$ & $\begin{array}{c}\text { Myocyte } \\
\text { transsectional } \\
\text { area }(\mathrm{AU}) \\
\text { (nean } \pm \mathrm{S} . \mathrm{D})\end{array}$ & $\begin{array}{c}\text { Capillary } \\
\text { index } \\
\text { mean } \pm \text { S.1 }\end{array}$ & $\begin{array}{c}\text { Capillary } \\
\text { transsectional } \\
\text { area (AU) } \\
\text { (mean } \pm \text { S.D. })\end{array}$ \\
\hline C I & 6 & l & 0 & $3.73 \pm 0.35$ & $3.11 \pm 0.42$ & $78.4 \pm 12.6$ & $840.5 \pm 79.1$ & $2.61 \pm 0.37$ & $170.6 \pm 31.2$ \\
\hline C. II & 6 & 2 & () & $3.86 \pm 0.39$ & $3.25 \pm 0.59$ & $81.3 \pm 14.1$ & $887.8 \pm 91.2$ & $2.88 \pm 0.29$ & $197.7 \pm 30.1$ \\
\hline C III & 6 & 6 & 0 & $3.81 \pm 0.45$ & $3.27 \pm 0.43$ & $82.5 \pm 15.6$ & $922.7 \pm 81.1$ & $3.15 \pm 0.32$ & $2(12.9 \pm 32.0$ \\
\hline G IV & 6 & 8 & 0 & $3.94 \pm 0.43$ & $3.41 \pm 0.49$ & $79.6 \pm 13.0$ & $896.0 \pm 75.0$ & $3.01 \pm 0.39$ & $193.0 \pm 29.2$ \\
\hline CV & 3 & 12 & 0 & $4.15 \pm 0.49$ & $3.62 \pm 0.57$ & $82.3 \pm 14.5$ & $885.6 \pm 69.2$ & $2.94 \pm 0.40$ & $196.6 \pm 31.4$ \\
\hline C VII & 4 & 16 & 0 & $4.29 \pm 0.41$ & $3.87 \pm 0.54$ & $80.7 \pm 17.5$ & $892.1 \pm 63.2$ & $3.16 \pm 0.33$ & $181.5 \pm 33.9$ \\
\hline DOX I & 6 & 1 & 4 & $3.89 \pm 0.58^{\dagger}$ & $3.28 \pm 0.37 \dagger$ & $81.3 \pm 13.5 \dagger$ & $883.5 \pm 85.6 \dagger$ & $2.74 \pm 0.46)^{1}$ & $185.8 \pm 43.3 \dagger$ \\
\hline DOX II & 6 & 2 & 8 & $4.78 \pm 0.42^{* *}$ & $3.72 \pm 0.31^{*}$ & $95.3 \pm 12.2^{*}$ & $995.6 \pm 75.4^{*}$ & $2.98 \pm 0.50$ & $172.8 \pm 42.5 \dagger$ \\
\hline DOX III & 6 & 6 & 16 & $5.42 \pm 0.57^{* * *}$ & $3.80 \pm 0.41^{*}$ & $108.6 \pm 11.1^{* *}$ & $1170.5 \pm 93.2^{* *}$ & $3.33 \pm 0.42^{+}$ & $168.3 \pm 44.1 \dagger$ \\
\hline DOX IV & 6 & 8 & 24 & $5.35 \pm 0.55^{* * *}$ & $4.24+0.43^{* *}$ & $194.7 \pm 18.2 * * *$ & $1261.0 \pm 110.1^{* *}$ & $3.60 \pm 0.57^{*}$ & $158.7 \pm 49.3^{*}$ \\
\hline DOX V & 6 & 12 & 24 & $5.22 \pm 0.40^{* * *}$ & $4.28 \pm 0.30^{* *}$ & $116.0 \pm 24.6^{* *}$ & $1002.1 \pm 87.2^{* *}$ & $3.66 \pm 0.48^{*}$ & $160.1 \pm 48.4^{*}$ \\
\hline DOX VI & 6 & 14 & 24 & $5.13 \pm 0.56^{* *}$ & $4.10 \pm 0.39^{*}$ & $111.5 \pm 17.8^{* *}$ & $995.5 \pm 88.4^{*}$ & $3.85 \pm 0.38^{* *}$ & $160.5 \pm 57.6^{*}$ \\
\hline DOX VII & 6 & 16 & 24 & $4.78 \pm 0.63^{* *}$ & $4.24 \pm 0.48^{*}$ & $114.4 \pm 16.4^{* *}$ & $964.3 \pm 78.7^{*}$ & $3.91 \pm 0.30 * *$ & $154.4 \pm 56.6^{*}$ \\
\hline DOX VIII & 6 & 20 & 24 & $4.84 \pm 0.41^{* *}$ & $4.20 \pm 0.36^{*}$ & $117.9 \pm 13.9^{* *}$ & $982.6 \pm 92.8^{*}$ & $4.29 \pm 0.42^{* *}$ & $132.2 \pm 48.5^{* *}$ \\
\hline
\end{tabular}

$* P<0.05, * * P<0.01, * * * P<0.001$, t not significant. 

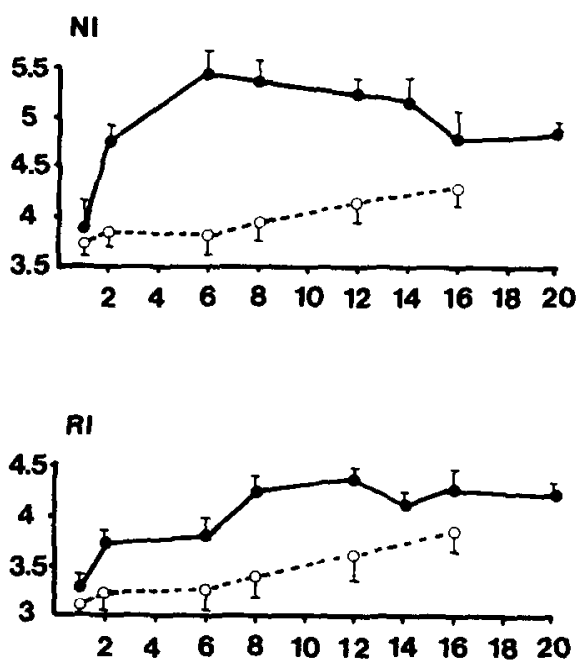

$\mathrm{Cl}$

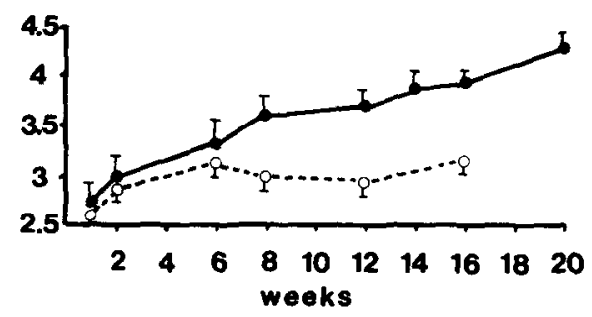

Fig. 1. Mean values \pm S.E.M. of nuclear index, reticulin index and capillary index during 20 weeks in mice. Solid lines show results of the DOX-treated mice whereas dotted lines with open circles show results of the control mice.

been well documented in the heart of various species with both light microscopic and electron microscopic examination $[1,2,3,4,10-12]$. In contrast to our previous study applying morphometry in dilated hearts [9], all hearts in the present study were examined in a contracted state, achieved by their immersion in a $\mathrm{CaCl}_{2}$ solution. This change in methodology was introduced because of our observation that most of the morphometric parameters are sensitive to dilatation [8]. Our results have shown a close relationship between the cumulative dose of DOX and its effect on the morphometric parameters studied. During the observation time all six parameters changed with a consistent pattern. RI increased with the cumulative dose of DOX and remained stable following the last injection. The level of significance decreased after the end of DOX treatment because of the gradual increase in RI in the control group. The reason for this phenomenon is unclear, but may be related to the age of the animals. Reticulin is the first protein to appear during the course of reactive repair fibrosis [13]. An increase in RI may be unfavourable for the functional state of the heart with respect to plasticity, elasticity and compliance.

The remarkable increase in NTA was also correlated with the cumulative dose of DOX. After the last DOX injection a plateau level was observed which was slightly lower than the peak value. The increase in NTA may be related to the nuclear 'swelling' which has previously been reported in microscopical studics [11]. It has been suggested that the nuclear alterations are the results of unravelling and disaggregation of chromatin induced by the intercalating action of DOX [4]. It is known that DOX binds very strongly and very fast to DNA [14] and therefore must cross the nuclear membrane. The observed swelling may also be the result of an effect on the nuclear membrane, which is crossed by DOX. Nevertheless, the increase in NTA appears, to a certain extent, to be irreversible, suggesting that repair mechanisms available are not capable of adequately restoring the original state.

The increase in NI during DOX treatment correlated well with an increase in the number of endothelial cells. The gradual increase in NI in the control group, which is likely to be an aging phenomenon, resulted in a gradual drop in the level of significance for the difference between that in the DOX treated group and that in controls from $P<0.001$ to $P<0.01$. The increase in MTA was followed by a drop during the period after the completion of DOX treatment. This finding has
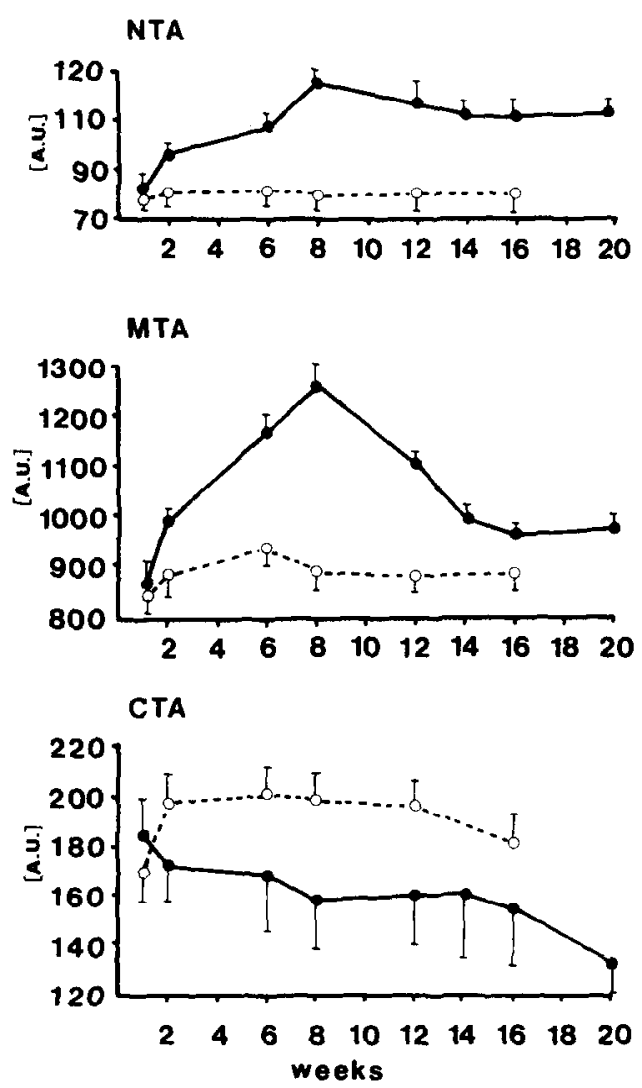

Fig. 2. Mean values \pm S.E.M. of nuclear transsectional area, myocyte transsectional area and capillary transsectional area during a 20 week period. Values are expressed in arbitrary units (AU) calculated by the computer from digitized data. Solid lines show results of the DOX-treated mice and dotted lines show results of the control mice. 
several possible explanations. It may be related to an increase in the fibre volume during DOX administration followed by a loss of fibres during a period of repair. In this respect it is of interest that the turnover rate of contractile proteins is in the order of 1-2 weeks [15]. Another reason may be a change in the cell membrane caused by an interaction with DOX. Finally, myocyte 'swelling' may be the result of an uptake of water through a damaged cell membrane, a process which may be reversed to a certain extent after exposure to DOX is discontinued.

The increase in CI during and after DOX treatment may have been triggered by primary endothelial cell damage, considering the fact that these cells are even more vulnerable to DOX than myocytes [16]. Furthermore, an increase in CI may in addition be a phenomenon secondary to myocardial dysfunction, reduced perfusion and ischaemia. In this context it is of interest to note that in cases of endothelial damage induced by irradiation the final stage is described as marked fibrosis [17]. These changes are known to be mediated by peroxidation due to the generation of free radicals. The same mechanisms have also been considered to be of importance in mediating DOX-induced cardiotoxicity [18].

Overall CTA dropped in DOX-treated mice, correlating with the CI because of the inverse relationship of these two parameters. The large deviation of CTA is a result of a mixed population of 'old' capillaries with a normal CTA and newly formed capillaries with a very small CTA.

A great number of morphological changes in the heart after DOX administration have been described in the literature. Characteristic myocardial lesions include vacuolization, oedema, myocytolysis, fibrosis, ultrastructural changes in nuclear, myofibrillar, mitochondrial and sarcotubular organelles [12]. The final stage is complete destruc- tion and lysis of individual cardiac myocytes replaced by fibrosis [4]. A grading system, which uses a subjective method based on endocardial biopsies of the human heart, has been proposed by Billingham et al. [19] and has been used for comparative studies in animal models $[1,10]$. The present study was a histomorphometric analysis of hearts in mice and aimed to develop a quantitative model for the evaluation of anthracycline-incluced cardiotoxicity. Overall, the changes in RI, NTA, CI and CTA observed with the present quantitive model are irreversible. The CI and CTA reached their highest level of significance after DOX treatment, indicating that the changes in these parameters occur slowly and are long lasting because repair of the injuries, if it occurs at all, takes a long time. NI and NTA correlate well with the cumulative DOX dose, while both parameters tend to return to normal after discontinuation of DOX treatment, suggesting that these changes are reversible.

Comparisons of the grading system used for the anthracycline-induced heart toxicity [5] with the quantitative morphometric analysis of heart tissuc after treatment with anthracyclines should be performed in order to gain some insight into the practical value of the latter method. Methods which allow a quantitation of heart tissue changes during an thracycline treatment would be better than qualitative descriptions of changes in the histomorphology of the heart. Morphometry, defined as the quantitative description of a given structure, is a possible way of achieving objective and reproducible results. In contrast to subjective grading systems [19], morphometry allows the quantitative description of a continuous spectrum of changes in heart morphology. Multi-variate analyses of morphometrical features are possible and will allow the inter-dependencies of the different parameters studied with this method to be evaluated.

\section{REFERENCES}

1. Bertazolli C, Bellini O, Magrini U, Tosana MG. Quantitative experimental evaluation of adriamycin cardiotoxicity in the mouse. Cancer Treat Rep 1979, 63, 1877-1883.

2. Bristow MR, Wayne A, Minobe BS et al. Anthracycline-associated cardiac and renal damage in rabbits. Lab Invest $1981,45,157-168$.

3. Iatropoulos MJ. Anthracycline cardiomyopathy: predictive value of animal models. Cancer Treat Symp 1984, 3, 3-17.

4. Young DM. Pathological effects of adriamycin in experimental systems. Cancer Chemother Rep 1975, 6, 159-175.

5. Billingham ME, Mason JW, Bristow MR. Anthracycline cardiomyopathy monitored by morphological changes. Cancer Treat Rep 1978, 62, 865-872.

6. Höfling B, Mendler N, Heimisch W, Boning L, Kolb HJ, Bolte HD. Tierexperimentelles Modell zur akuten und chronischen Adriamycin-Kardiotoxizität. In: Füllenbach D, Nagel GA, Seeber S, eds. Adriamycin Symposium, Beitr Onkol, Basel, Karger, 1981, Vol, 9, 49-63.

7. Scheulen ME. Biochemische Ursachen der kumulativen Anthracyclin-kardiotoxizität Ansatzpunkte für eine kardioprotektive Begeleit-therapie? In: Füllenbach D, Nagel GA Seeber S, eds. Adriamycin Symposium, Beitr Onkol, Basel, Karger, 1985, Vol. 9, 64-75.

8. Van Velzen D, Veldhuizen RW, Alons CL. Quantification of early myocellular and interstitial changes in drug toxicity studies. Pediatr Pathol 1986, 5, 319-320.

9. Van der Vijgh WJF, Van Velzen D, Van der Poort SEJM et al. Morphometric study of 
myocardial changes during puromycin aminonucleoside induced nephropathy in rats. Anticancer Res 1987, 7, 1111-1116.

10. Herman EH, El-Hage AN, Ferrans VJ, Ardalan B. Comparison of the severity of the chronic cardiotoxicity produced by doxorubicin in normotensive and hypertensive rats. Toxicol Appl Pharmacol 1985, 78, 202-214.

11. Solcia E, Ballerina L, Bellini $\mathrm{O}$ et al. Cardiomyopathy of doxorubicin in experimental animals. Factors affecting the severity, distribution and evaluation of myocardial lesions. Tumori 1981, 67, 461-472.

12. Zahringer J. Clinical features of the adriamycin cardiomyopathy. Heart Bull 1982, 13, 87-94.

13. Florey H. General Pathology. London, Lloyd-Lyk, 1964, 317.

14. Arcamone F. Antitumor anthracyclines: recent developments. Med Res Rev 1984, 4, 153-188.

15. Ferrans W. Morphologic assessment of cardiac lesions caused by anthracyclines. In: Muggia FW, Young CW, Carter SK, eds. Anthracycline Antibiotics in Cancer Therapy. Boston, Martinus Nijhoff, 1982, 331-348.

16. Wenzel DG, Cosma GN. A model system for measuring comparative toxicities of cardiotoxic drugs for cultured rat heart myocytes, endothelial cells and fibroblasts. II Doxorubicin, 5fluorouracil and cyclophosphamide. Toxicology 1985, 33, 117-128.

17. Fajardo LF, Stewart JR. Pathogenesis of radiation induced myocardial fibrosis. Lab Invest 1973, 29, 244-257.

18. Meyers CE, Mirindi J, Batist G, Haim N, Sinha BK. Anthracyclines. In: Pinedo HM, Chabner BA eds. Cancer Chemotherapy Annual, Amsterdam, Elsevier, 1984, Vol. 7, 57-75.

19. Billingham ME, Bristow MR. Evaluation of anthracycline cardiotoxicity: predictive ability and functional correlation of endomyocardial biopsy. Cancer Treat Symp 1984, 3, 71-76. 